\title{
Het afschalen van het Afrikaans: Een politieke stommiteit
}

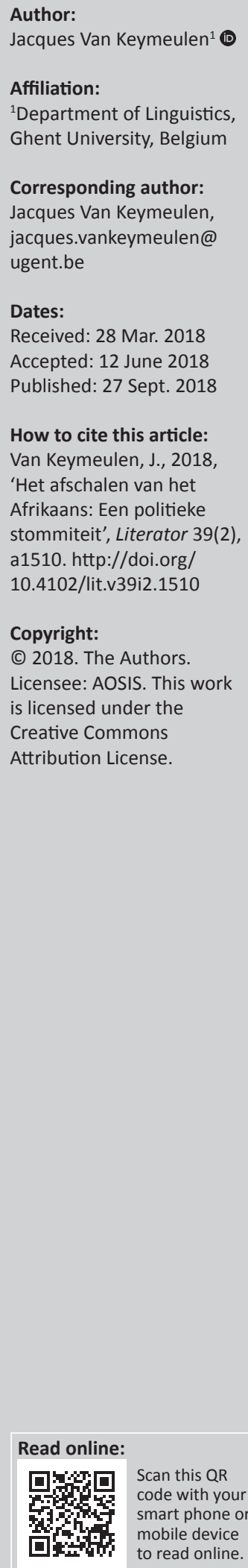

\begin{abstract}
The downgrading of Afrikaans: A political stupidity. Afrikaans is a partly creolised language, based on Dutch (dialects). It originated as the lingua franca of the dominated population of servants and slaves (the bruinmense), and was taken over by the dominant white population, which standardised it and developed it into a fully-fledged cultural language, comparable with other small Germanic languages such as Danish or Norwegian. It is the only example of a 'creoloid' that reached that level. Politically, it is a very bad idea to downgrade Afrikaans as a language of instruction at universities. This will lead to frustration and a renewed rise of Afrikaner nationalism. One should avoid unnecessary political tensions in a country that has to face matters that are far more urgent, such as the racially based inequality in wealth.
\end{abstract}

\section{Inleiding}

De bachelorcursus Afrikaans: Taal- en Letterkunde aan de Gentse Universiteit bestaat sinds 2007. In het academiejaar 2018-2019 komt er ook een cursus op masterniveau: Talen en Literaturen van Zuid-Afrika. Bovendien is er nu ook (sedert 2018) de leerstoel Zuid-Afrika: Talen, Literaturen, Cultuur en Maatschappij. De eerste leerstoelhouder was prof. Hein Willemse (2017-2018); de tweede wordt prof. Wannie Carstens (2018-2019). Het is de bedoeling telkens te wisselen tussen letterkunde en taalkunde. Het Gentse Centrum voor Afrikaans en de studie van Zuid-Afrika zit dus niet stil. Het organiseert ook seminaries, congressen, een leeskring, lezingen en filmvertoningen. De activiteiten worden nu ook kenbaar gemaakt via de Nieuwsbrief op LitNet, die door Yves T'Sjoen wordt verzorgd. Daar komt overigens nog bij dat de Gentse Universiteit een van de weinige Europese universiteiten is met een volledige vierjarige opleiding in de 'Afrikaanse Talen en Culturen' (met Afrikaans wordt hier dan wel zwart Afrika bedoeld). De tweetalige schoolwoordenboeken voor Zoeloe/Engels en Xhosa/Engels, bijvoorbeeld, worden wel in Oxford uitgegeven, maar werden samengesteld onder de leiding van de Gentse professor Gilles-Maurice de Schryver.

Het is vreemd te moeten constateren dat de stijgende belangstelling voor het Afrikaans in Gent de vakken Afrikaans worden door tientallen studenten gevolgd - blijkbaar gelijke tred houdt met de afschaling van het Afrikaans in Zuid-Afrika zelf - meer bepaald als taal van het hoger onderwijs. Uiteraard wordt een en ander in Gent met leedwezen gadegeslagen. Ik denk dat vooral Vlamingen gevoelig zijn voor het verdwijnen van het Afrikaans als taal van de wetenschap. De Vlamingen hebben immers zelf een jarenlange strijd moeten voeren voor universitair onderwijs in de eigen taal, het Nederlands. Pas in 1930 was het zover: de Gentse Universiteit werd vernederlandst (Leuven volgde pas later); men was bereid de internationaliteit van de hele universiteit, die tot dan toe dankzij de Franse instructietaal inderdaad sterk internationaal gericht was, meer bepaald voor de ingenieurswetenschappen, op te offeren om Vlamingen in het eigen taal les te laten volgen. 'Á un corps flamand, il faut une tête flamande ${ }^{1}$, zei August Vermeylen, de eerste rector van de vernederlandste universiteit in de Belgische Senaat (en overigens in het Frans!).

\section{Afrikaans als Apartaans? ${ }^{2}$}

Het is bekend dat Afrikaans door een meerderheid van de zwarte bevolking wordt geassocieerd met de apartheidsperiode. Apartheid werd inderdaad voor een groot deel ontworpen en gedragen door Afrikaanstalige politici. De poging tot het invoeren van Afrikaans in de middelbare scholen heeft in de jaren 70 van de vorige eeuw tot zware onlusten geleid die het einde van het apartheidsregime hebben ingeluid. Het feit dat Afrikaans vooral de taal van de bruinmense is - in zowel absolute als relatieve cijfers - wordt doorgaans vergeten.

1.Bij een Vlaams lichaam hoort een Vlaams hoofd

2.De term is van Breyten Breytenbach. 
Het 'taalverhaal' dat Afrikaans de taal is van de onderdrukkende witmense, moet dringend voor een ander ingeruild worden. In mijn cursus Afrikaans in Gent houd ik mijn studenten samenvattend het volgende voor (en ik denk daarbij vrij goed bij de historische realiteit aan te sluiten): Het Afrikaans is gebaseerd op de Zuid-Hollandse volkstaal die na 1652 aan de Kaap werd ingevoerd. Die taal werd gaandeweg zowel door de inheemse als door de ingevoerde bevolking overgenomen, al is het mogelijk dat sommige Khoikhoin ook voordien al wat Nederlands konden spreken in hun contacten met voorbijvarende schepen. Ze hebben er echter Afrikaans van gemaakt. Ik ga dus akkoord met de ideeën van Hans den Besten (1989), die een onderscheid maakt tussen ProtoAfrikaans I, een gecreoliseerd Nederlands dat gesproken werd door de gedomineerde bevolking van slaven en knechten, en Proto-Afrikaans II, het Kaaps-Hollands dat door de blanken werd gesproken. Beide varianten zijn in de loop van de 19de eeuw met elkaar versmolten; de standaardisering gebeurde op basis van het Oostgrensafrikaans. De verschillen met het Nederlands, meer bepaald de vereenvoudigde morfologie, zijn een uitvloeisel van Proto-Afrikaans I; het feit dat Afrikaans zo goed op het Nederlands is blijven lijken, is het gevolg van Proto-Afrikaans II. Bij de standaardisering en vooral na de erkenning van Afrikaans als officiële taal in 1925 heeft er overigens een 'vernederlandsing' plaatsgevonden, vooral op het gebied van de woordenschat.

Mijns inziens lijdt het geen twijfel dat Afrikaans een creoliseringsproces heeft doorlopen, al besef ik dat dat idee nog steeds controversieel is. Het Nederlands is in de 17de eeuw naar Zuid-Afrika overgeplant. Normaal zou dan te verwachten zijn dat de taal blijft voortbestaan in een archaïsche vorm. Er zijn namelijk heel wat voorbeelden aan te wijzen van talen die in hun ontwikkeling zijn blijven stilstaan zodra ze om een of andere reden naar verre oorden geëxporteerd werden en in een isolement geraakten. De Franse spreektaal in het Canadese Quebec staat dichter bij het 17de-eeuwse Frans dan het bij het huidige Frans. ${ }^{3}$ Een mooi voorbeeld is ook het IJslands, een taal waarvan de morfologie de laatste 1000 jaar grotendeels onveranderd is gebleven, puur vanwege haar isolement. Een hedendaagse IJslander zou nog met een Noorse kolonist uit pakweg de 10de eeuw een conversatie kunnen voeren (zie in dat verband Braunmüller 1991:171).

Het Nederlands is in Zuid-Afrika volstrekt niet blijven stilstaan, maar is razendsnel beginnen te veranderen. Dat kan het beste verklaard worden door het feit dat dat Nederlands in andere monden dan in die van de Nederlanders is terechtgekomen. Vanaf het einde van de 17de eeuw werd de Kaapkolonie inderdaad steeds veelkleuriger en meertaliger, vooral door de aanvoer van slaven uit zowel Afrika als Azië die de al bestaande rijkdom aan talen (zowel Europese talen als inheemse Khoisantalen) aan de Kaap nog kwam vermeerderen. Het Afrikaans is mijns inziens in eerste instantie ontstaan als lingua franca bij de gedomineerde, gekleurde, bevolking die dringend een gemeenschappelijk communiecatiemiddel nodig had, en de taal van 'de baas' overnam, maar wel in een vernieuwde vorm.

Taal heeft twee belangrijke functies: efficiënte communicatie en expressie van culturele identiteit van de taalgemeenschap. Ik meen dat de nieuwe sprekers van het Nederlands in Zuid-Afrika enkel uit waren op communicatie en zich met de taal niet cultureel identificeerden, zodat er geen belangstelling was om de taal 'correct' te praten. Een heleboel morfologische complexiteiten van het Nederlands werden op een paar generaties tijd daarom overboord gegooid. ${ }^{4}$ Een mooi voorbeeld vormen de sterke werkwoorden (als in vinden - vond - gevonden). Het systeem is al eeuwen onregelmatig, maar elke nieuwe generatie ouders in Nederland en Vlaanderen let erop dat de kinderen de sterke werkwoorden één voor één correct leren gebruiken. Een Vlaamse ouder let erop dat een kind leert dat een tafel vrouwelijk is (ze is kapot), maar een stoel mannelijk (hij is kapot). ${ }^{5}$ Dergelijke onderscheidingen, die de communicatie op geen enkele wijze vooruithelpen, werden in Zuid-Afrika moeiteloos weggelaten - mijns inziens niet zozeer uit onvermogen om de taal goed te leren of door gebrekkige observatie door de leerders, maar uit desinteresse. Een dergelijk vereenvoudigingsproces kan waarschijnlijk op gang komen ook zonder dat er invloed van een of andere substraattaal aangewezen moet worden.

De nieuwe gecreoliseerde taalvorm die zo ontstond, het Afrikaans, is dus in eerste instantie een product van de kleurlingengemeenschap. Het was (is) hùn taal. De blanken hebben gaandeweg die taal overgenomen. Het is natuurlijk een ideologisch standpunt, en kort door de bocht, om te zeggen dat de blanken de taal van hun eigen slaven zijn gaan praten, maar ik denk dat die stelling toch dichter aansluit bij de historische realiteit dan een 'spontane' ontwikkeling van het Kaaps-Hollands naar het Afrikaans (weliswaar met inbreng van andere talen). De blanke Nederlandstaligen waren in de beginjaren van de Kaapkolonie erg laag geschoold - een beperkt aantal VOC-ambtenaren niet te na gesproken - en kwamen vooral in de Kerk met (geschreven?) Standaardnederlands in contact. Bovendien werd hun relatieve aantal steeds kleiner in vergelijking met de gekleurde (bruin en zwart) bevolking. Bovenal lieten ze de zorg voor hun kinderen dikwijls over aan bedienden en slaven van wie de taal dan op jonge leeftijd werd overgenomen.

De blanke Afrikaanstaligen hebben echter een zeer belangrijke bijdrage aan de taal van de bruinmense geleverd. Ze hebben het Afrikaans gestandaardiseerd-overigens zonder die bruinmense daarbij te betrekken - en de taal tot een moderne cultuurtaal opgekweekt, die alle hogere maatschappelijke functies kon vervullen: taal van hoger onderwijs, van wetenschap en van rechtspraak. De vernederlandsing die daarmee gepaard ging, heeft ervoor gezorgd dat Nederlands en Afrikaans tot op zeer grote hoogte onderling verstaanbaar zijn. Afrikaanstaligen en

4.Een opmerkelijke uitzondering is de attributieve verbuiging. Het Afrikaans heeft de verbuiging overgenomen, maar ze wordt beregeld op een manier die complexer is dan in het Nederlands.

5. Het onderscheid tussen mannelijk en vrouwelijk is in Nederland wel grotendeels verloren gegaan; in de Nederlandse standaardtaal heeft men het nu over het- en de-woorden (resp. al dan niet onzijdig). 
Nederlandstaligen kunnen in een gesprek inderdaad met elkaar gewoonweg hun eigen taal blijven praten.

Afrikaans heeft waarschijnlijk (het zou eens gekwantificeerd moeten worden) ongeveer dezelfde culturele output als de kleinere Germaanse talen als Zweeds, Noors of Deens. ${ }^{6}$ Noors en Deens hebben overigens minder moedertaalsprekers dan Afrikaans. Het Afrikaans is overigens de enige taal die op een 'koloniale' taal is gebaseerd en die het tot het niveau van een volkomen cultuurtaal heeft gebracht. Er bestaan in de wereld tientallen talen die uit een koloniale taal (Frans, Engels, Spaans, Portugees) zijn ontstaan, en sommige daarvan zijn schrijftaal geworden, waarin hoogstaande literatuur is geschreven, of hebben allerlei rechten verworven. Het Papiaments (een creooltaal gebaseerd op het Spaans/Portugees), bijvoorbeeld, heeft een officiële status gekregen op de Benedenwindse Eilanden van de Nederlandse Antillen (Curaçao, Bonaire, Aruba) en is de voertaal van de lagere scholen. Afrikaans is echter als enige 'zustertaal' van een koloniale taal werkelijk de gelijke geworden van de 'gevestigde' talen in Europa.

\section{Een politieke stommiteit?}

De berichten over het lot van het Afrikaans aan de ZuidAfrikaanse universiteiten zijn treurig om aan te horen. Onder druk van kleine, maar zeer luide, groepen taalactivisten is er in het hoger onderwijs een diepgaande verengelsing begonnen. ${ }^{7}$ Het valt daarbij op dat Engels in tegenstelling tot het Afrikaans blijkbaar niet als een 'koloniale' taal wordt beschouwd, en dat voor zover ik dat kan overzien de zwarte taalactivisten volstrekt niet voor de eigen talen opkomen. Emancipatie is voor hen verengelsing. Engels is nochtans de taal van Cecil Rhodes, en is internationaal geworden enkel en alleen door de massale kolonisatie door de Engelsen van een zeer groot deel van de wereld.

Afrikaans is de enige Zuid-Afrikaanse taal die na de afschaffing van de apartheid statusverlies heeft geleden. Het officiële beleid is erop gericht om de 11 officiële talen gelijk te behandelen, maar dat heeft - niet als expliciete bedoeling, maar wel als effect - dat het Afrikaans een dramatisch functieverlies lijdt als taal van universitair onderwijs. Een overheid is echter ook verantwoordelijk voor de effecten van een beleid, zo lijkt mij. Het is echter zaak de zwarte talen maatschappelijk 'op te tillen', zonder tegelijk het Afrikaans neer te halen. Het is zeer de vraag of Engels / Afrikaans dubbelmedium-onderricht, door lessen tweemaal te geven in de verschillende talen, of door het inzetten van vertalers en tolken, op termijn een oplossing kan bieden. Men probeerde iets dergelijks ook aan de Gentse Universiteit in de jaren 20 van de vorige eeuw (nl. Nederlands en Frans proberen te verzoenen aan dezelfde instelling), maar dat bleek niet vol te houden. Een dergelijke tweetaligheid leidt gaandeweg opnieuw naar eentaligheid ten voordele van de dominante taal.

6. Het zou interessant zijn om de culturele output van de verschillende talen eens te vergelijken: aantal uren radio / TV, aantal boeken, aantal universiteiten met de taal als onderwijstaal, enz. enz.

7.Verengelsing van het hoger onderwijs is ook aan de orde aan de Nederlandse en Vlaamse universiteiten, maar daar gebeurt dat niet onder dwang en is ze-zeker in Vlaanderen - minder virulent.
In België hebben de taalperikelen tussen de Nederlandstalige Vlamingen en de Franstalige Walen (en Vlamingen ${ }^{8}$ ) uiteindelijk geleid tot een federale staatsstructuur die via herhaaldelijke staatshervormingen steeds verder wordt uitgebouwd. Taal en identiteit zijn zeer belangrijk; het Belgische voorbeeld geeft aan dat het geen goed idee is om een taalgemeenschap taalrechten - met inbegrip van het gebruik van de taal als instructietaal aan universiteiten - te ontzeggen. Daar komt geheid herrie van.

Het Afrikaans is een volledig uitgebouwde cultuurtaal die door de overheid uit welbegrepen eigenbelang gekoesterd zou moeten worden. Niet alleen is het de taal van een belangrijk deel van de bevolking; bovendien is een groot deel ervan, met name de witmense, hoog opgeleid en vrij welvarend. Het blijvend frustreren van die groep kan leiden tot onnodige politieke onrust die de aandacht afleidt van de strijd tegen het werkelijke probleem van het land, namelijk de nog steeds grotendeels raciaal bepaalde schrijnende ongelijkheid in rijkdom en welvaart, het gevolg van de apartheidsjaren. Wie Afrikaans echter blijvend met racisme en apartheid blijft associëren, leeft vooral in het verleden; de rekening van de apartheid wordt tegenwoordig steeds meer gepresenteerd aan (jonge) mensen die voor dat regime niet verantwoordelijk zijn geweest. De democratie in Zuid-Afrika is tegenwoordig toch al 24 jaar oud! Bovendien is het Afrikaans een vanzelfsprekende taal voor het onderwijs - ook op het hoogste niveau - voor de bruinmense, die toch de meeste moedertaalsprekers van het Afrikaans uitmaken. Ze worden nu - eindelijk - ook bij de (her)standaardisering van hun taal betrokken. Een laatste maar niet zo vaak vermeld argument om het Afrikaans als cultuurtaal en taal van hoger onderwijs te behouden en te bevorderen is het feit dat ze een band schept met Nederland en Vlaanderen. Wie de Nederlandse cultuur maar klein vindt, wijs ik altijd graag op het feit dat het bruto binnenlands product - een maat voor de economische kracht van een land van de Benelux (Nederland, België, Luxemburg = 'de Lage Landen') ongeveer even groot is als dat van de Russische Federatie. ${ }^{9}$ De culturele boycot tijdens de apartheid heeft het bewustzijn van de taalverwantschap tussen Afrikaans en Nederlands geen goed gedaan; daar is nog werk te verzetten!

\section{Conclusie}

De vraag is op welke manier het beleid van de overheid met betrekking tot het Afrikaans een element kan zijn in het naderbij brengen van oplossingen voor de problemen van het land. Ik denk dat heel wat mensen heimwee beginnen te krijgen naar het discours van Nelson Mandela over verzoening. De overheid is volgens mij hier het verkeerde pad opgegaan. Ik meen dat het aanwakkeren van 'Afrikanernationalisme' niet echt een goed idee is, en dat de re-introductie van wat 'struggle' (om electorale redenen?) contraproductief zou kunnen werken. Mandela begreep dat 8.In de 19 de eeuw was de hogere burgerij in de viaamse steden sterk verfranst.

9.Schatting voor 2016 van de Verenigde Naties (zie https://en.wikipedia.org/wiki/ List_of_countries_by_GDP_(nominal), geconsulteerd op 15.03.2018): in miljoen dollar: Rusland $\overline{1} .246 .015-$ Benelux 1.310 .056 (= Nederland 777.227, België 467.955, Luxemburg 64.874). 


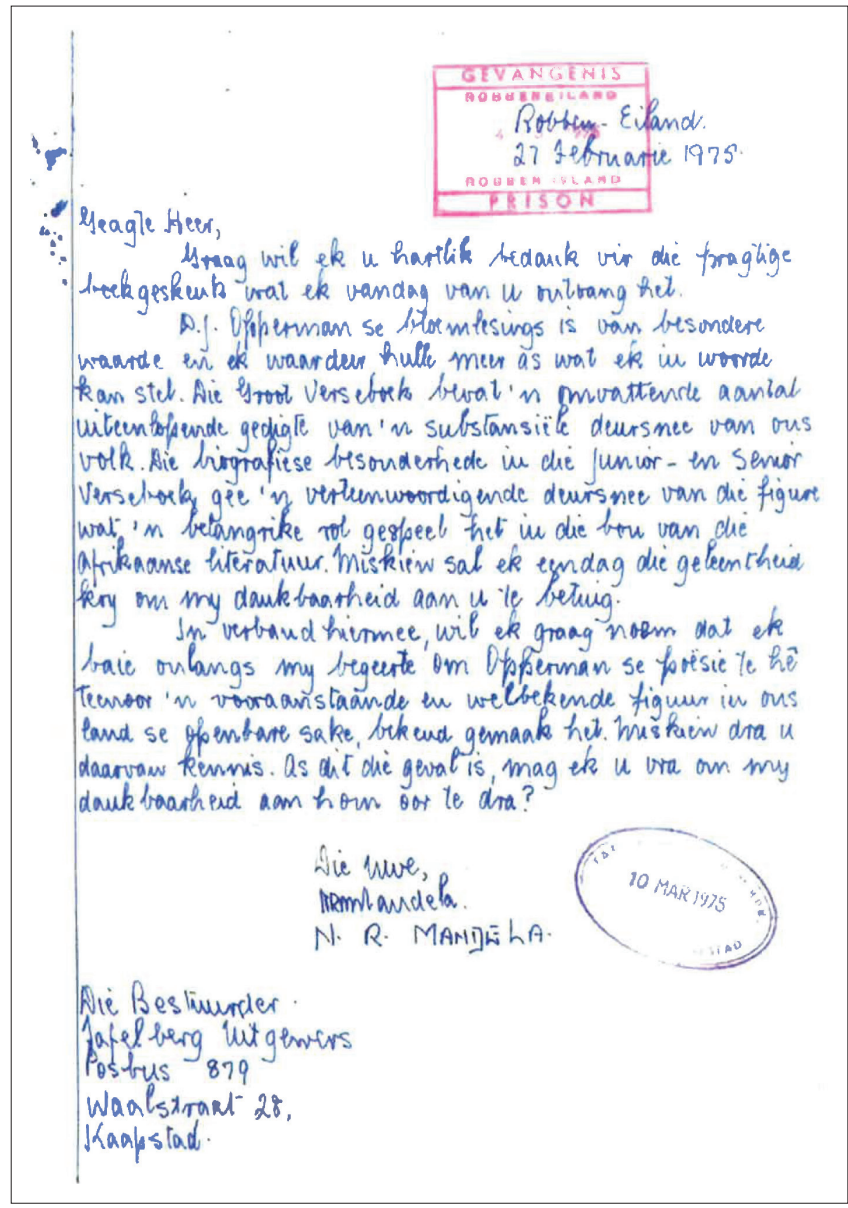

Bron: Maroela Media, 2013, 'Mandela se Afrikaans brief uit die tronk', 06 Desember, geconsulteerd op 17 Juli 2018, van https://maroelamedia.co.za/nuus/mandela-seafrikaanse-brief-uit-die-tronk/

Notitie: oorspronkelijke brief wordt bewaard in een kluis bij NB Uitgewers, Kaapstad. FIGUUR 1: Bedankingsbrief van Nelson Mandela aan Tafelberg Uitgewers. de installatie van de apartheid mede was ingegeven door de angst van de Afrikaners om samen met hun privileges - die ze overigens deelden met de blanke Engelstaligen - ook hun taal en cultuur te verliezen, aangezien ze als taalgemeenschap geminoriseerd waren geraakt. Die angst zou door de huidige beleidsmensen weggenomen moeten worden. Ik zou willen besluiten met een brief van Nelson Mandela (zie Figuur 1 [Maroela Media 2013]) geschreven vanuit de gevangenis van Robbeneiland, die laat zien dat hij perfect Afrikaans kon schrijven en in zijn barre omstandigheden de moeite heeft genomen de literatuur van het Afrikaans grondig te bestuderen. Indien men zich opnieuw door zijn verzoenende houding zou laten inspireren, zou een en ander misschien nog ten goede kunnen keren.

\section{Dankwoord Concurrerende belangen}

Ik verklaar dat ik geen financiële of persoonlijke relaties heb die me ten onrechte hebben beïnvloed bij het schrijven van dit artikel.

\section{Referenties}

Braunmüller, K., 1991, 'Isländisch', in Die skandinavischen Sprachen im Überblick, pp. 170-209, Francke, Tübingen.

Chevalier, G., 2008, 'Les français du Canada: Faits linguistiques, faits de langue', Alternative Francophone 1(1), 80-97.

Den Besten, H., 1989, 'From Khoekhoe foreignertalk via Hottentot Dutch to Afrikaans: The creation of a novel grammar', in M. Pütz en R. Dirven (eds.), Wheels within wheels: Papers of the Duisburg symposium on Pidgin and Creole Languages, pp. 207-249, Verlag Peter Lang, Frankfurt am Main.

Maroela Media, 2013, 'Mandela se Afrikaans brief uit die tronk', 06 Desember, geconsulteerd op 17 Juli 2018, van https://maroelamedia.co.za/nuus/mandelase-afrikaanse-brief-uit-die-tronk/ 